\title{
Geophysics and cultural heritage: a living field of research for Italian geophysicists
}

\author{
S. Piro ${ }^{*}$, S. Negri², T.A.M. Quarta ${ }^{2}$, M. Pipan ${ }^{3}$, E. Forte ${ }^{3}$, M. Ciminale ${ }^{4}$, E. Cardarelli ${ }^{5}$, \\ P. Capizzi ${ }^{6}$ and L. Sambuelli ${ }^{7}$ demonstrate how geophysical techniques have been used to find, \\ restore and manage Italy's cultural heritage.
}

I

f one reads the World Heritage List 2002/2003, (http:// whc.unesco.org/archive/WHList02-ENG.pdf), a datum comes out with evidence: 12 countries have 253 World Heritage Sites (WHS) and all the 125 member countries have 586 WHS. Within these 12 countries Italy has 35 WHS corresponding to about $6 \%$ of the whole, followed by Spain, $5.8 \%$, France, $4.6 \%$, and the tenth has less than $2 \%$ of WHS. Cultural heritage is one of the greatest riches of Italy.

Europe, with China, is the land which has the most stratified history in the world, and Italy is likely to still have undiscovered settlements dating from the prehistoric age to the $18^{\text {th }}$ century. Some areas are totally unexplored, others have been only partially dug and there is clear evidence that archaeological remains extend around the discovered areas. Geophysical methods for archaeological exploration, in Italy, date back to the Fifties with the pioneering work of Fondazione Lerici, and still many surveys are carried out to find new sites or to plan the future activity in an open archaeological excavation. The conservation of the cultural heritage, art, crafts or buildings, involves constant restoration works. High resolution geophysics and micro geophysics techniques may contribute to facilitate the restoration of artworks or historical building elements. With respect to the management of a museum, micro geophysics techniques can contribute to evaluating the possibility and the precautions that have to be taken when moving artefacts either for a museum reorganization or for temporarily lending a masterpiece to an exhibition.

\section{Case histories}

The 'Soprintendenza Archeologica per il Lazio' (Italian Ministry of Cultural and Environmental Heritage) and the Institute of Technologies Applied to Cultural Heritage (ITABC-CNR) funded a research project to develop a method for combining the results of integrated geophysical prospection for creating a detailed archaeological interpretation. The project was carried out in 1999-2001. The selected archaeological site, situated on Altopiani di Arcinazzo (Roma), characterized by the presence of structures related to Traiano's Villa, was carried out using high-resolution GPR surveys along with a high-resolution fluxgate differential magnetic (FDM) survey. The GPR surveys were carried out over two seasons at Altopiani di Arcinazzo between 1999 and 2001 and it can be considered the first extensive highresolution GPR survey made in Italy to locate unknown archaeological structures. The geologic situation, and some preliminary excavations at the site, suggested that a GPR survey could adequately map subsurface structures at several metres deep. The primary goal for doing a ground remote sensing survey of the site was to determine as much as possible about the location, shape and purpose of any buildings that could be identified from the survey.

The Traiano's Villa was ascribed to be the villa of Emperor Marco Ulpio Traiano (AD98-117) after earlier archaeological excavations made during the $18^{\text {th }}-19^{\text {th }}$ century (Figure 1).

GPR surveys were performed employing a GSSI SIR $10 \mathrm{~A}^{+}$equipped with a 300 and $500 \mathrm{MHz}$ bistatic antenna with constant offset. A GPS survey, using a D-GPS Leica 520 in differential configuration, was made to position all the local grids into geo-referenced ones. Reflection data, collected in profiles with $50 \mathrm{~cm}$ spacing, were processed using standard techniques. Time slice analysis was applied to all the surveyed grids at the Villa of Traiano (Piro et al., 2003; Goodman and Piro, 2013).

From the time slices it is possible to interpret structures in the eastern portion of the investigated area to be related to private domus or palatium of the villa. This area is

\footnotetext{
${ }^{1}$ ITABC - CNR, Roma, Italy.

${ }^{2}$ Dipartimento di Scienze e Tecnologie Biologiche e Ambientali (DISTeBA), Universita del Salento Lecce, Italia.

${ }^{3}$ Dipartimento di Matematica e Geoscienze, Università di Trieste, Trieste, Italy.

${ }^{4}$ Dipartimento di Scienze della Terra e Geoambientali, Campus Universitario, Bari, Italy.

${ }^{5}$ DICEA - Università La Sapienza, Roma, Italy.

${ }^{6}$ Scienze della Terra e del Mare Università di Palermo, Palermo, Italy.

${ }^{7}$ DIATI - Politecnico di Torino, Torino, Italy.

"Corresponding author, E-mail: salvatore.piro@itabc.cnr.it
} 


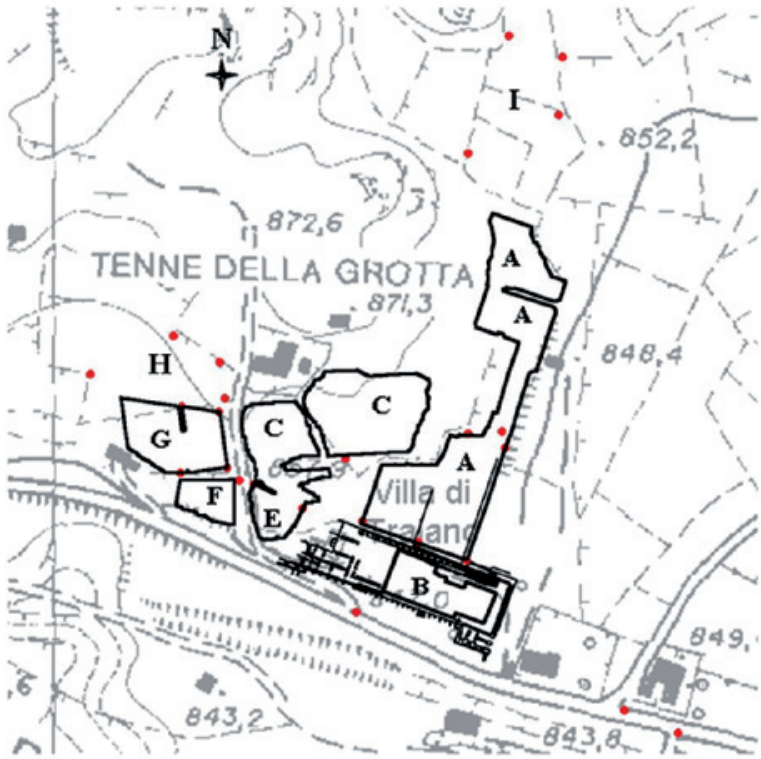

Traiano's Villa (Altopiani di Arcinazzo). GPR surveys 1999 - 2001 Location of the investigated areas: A, B, C, E, F, G.

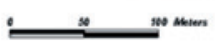

Figure 1 Location of the GPR surveys made at the Villa of Traiano, Rome.

characterized by the presence of many rooms, halls, corridors, exedras and baths associated with the private areas of the villa. Several mushroom-shaped anomalies (identified in Figure 2) are seen which are believed to be dipping pools in the bathhouse.
A group of quadrangular rooms, connected with each other and crossed by corridors, and semi-circular rooms were located with high resolution. These rooms were interpreted as thermal rooms (balnea). The westernmost feature shows an oval-shaped structure which has been interpreted by the archaeologists as an eel fishpond. Below this oval eel pond structure, square-shaped rooms also become visible in the GPR 3D rendering (Figure 3).

These weaker structures below the strong oval anomaly indicate that they are probably older structures. An isosurface rendering of the stronger reflection features at the Villa of Traianos is shown in Figure 3. The isosurface illuminated represents the $75^{\text {th }}$-strongest reflecting surface recording in the 3D volume. In 2012, the villa remains were cordoned off from the general public after the discoveries found with GPR showed the extent of the remains. The GPR reflection maps have helped the archaeologists to create a general vision of the layout of the villa, which will be indispensable when future excavations and partial restorations are begun.

A Ground-Penetrating Radar (GPR) survey was carried out in an urban area centrally located in Lecce (Italy), where archaeological structures are buried (Figure 4).

In this area, measuring approximately $10,000 \mathrm{~m}^{2}$, remnants of a historical Franciscan monastery built in 1432, subsequently enlarged, restructured and destroyed in 1971, are present. This area has been proposed to be transformed into a cultural centre, a covered market, and an underground carpark. A first excavation in the site brought to light parts of foundation walls, parts of the old floor in agreement

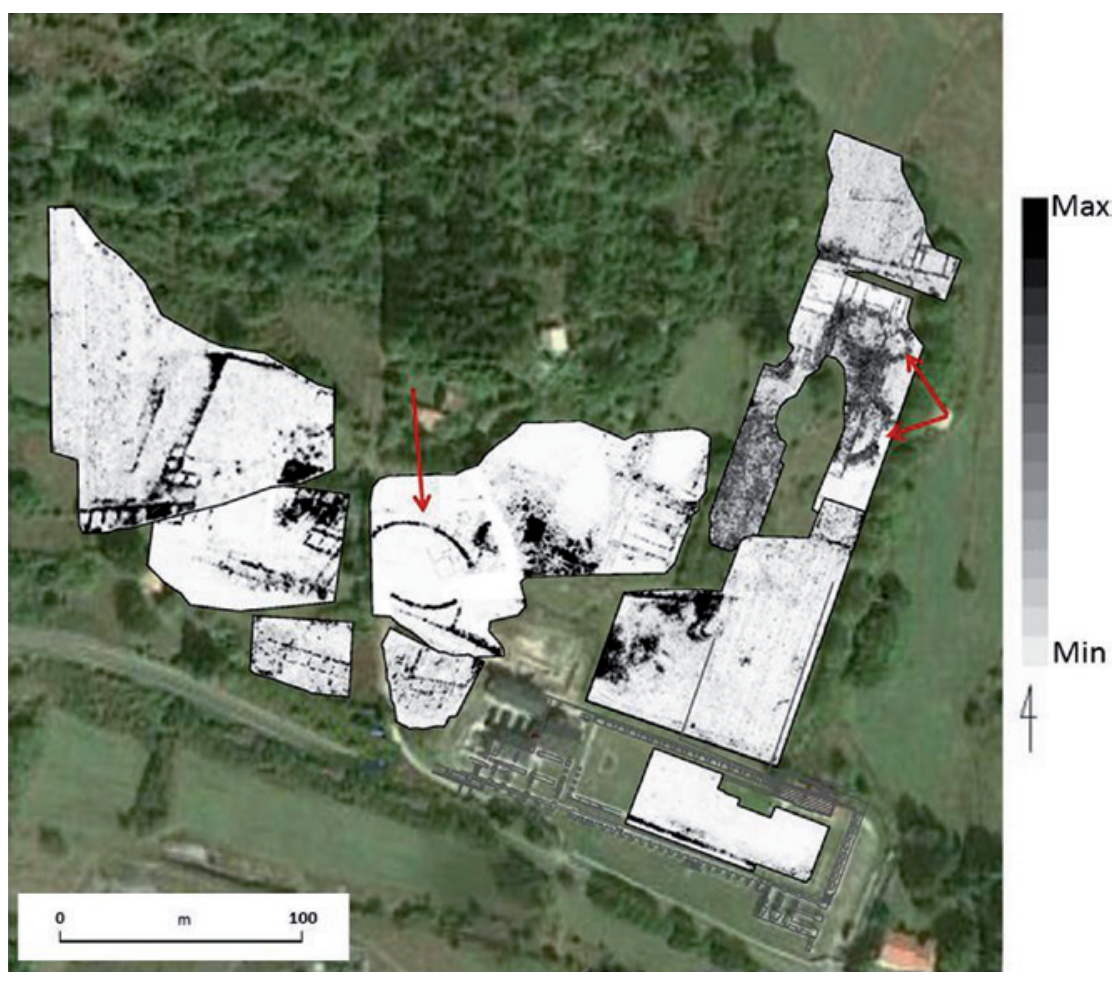

Figure 2 Overlay of some of the GPR survey grids on the Villa of Traiano site map located with GPS. 


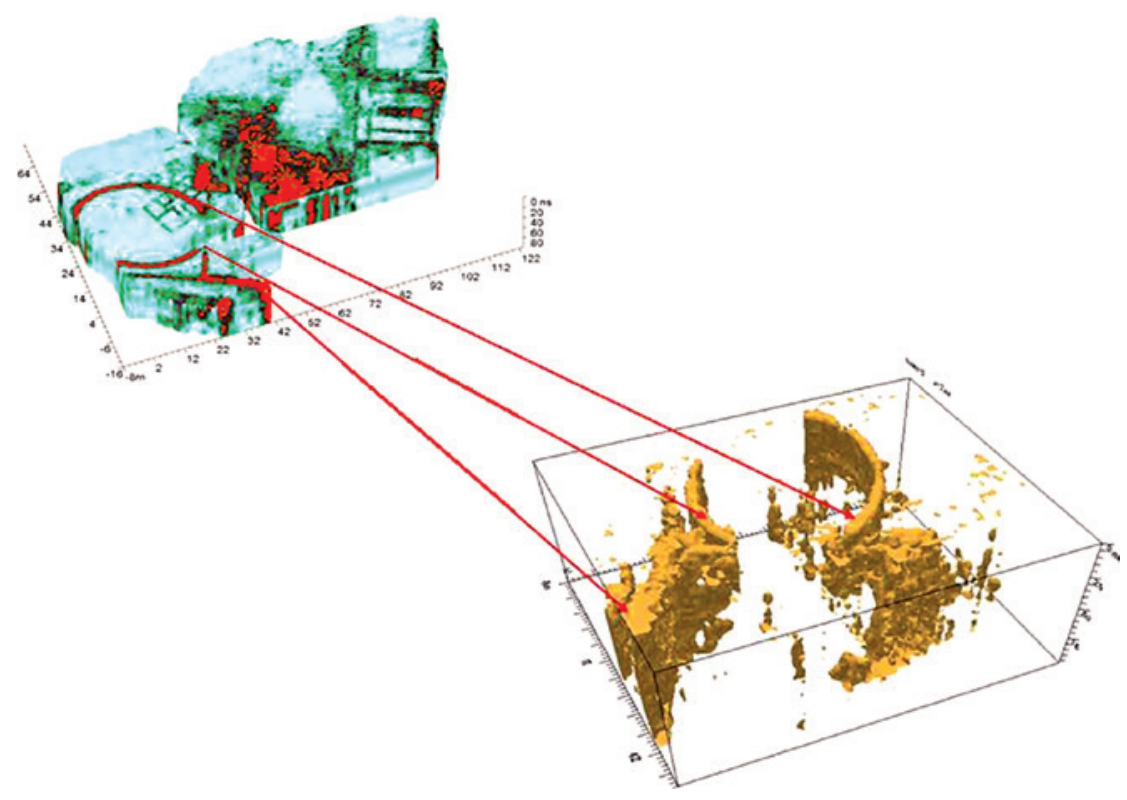

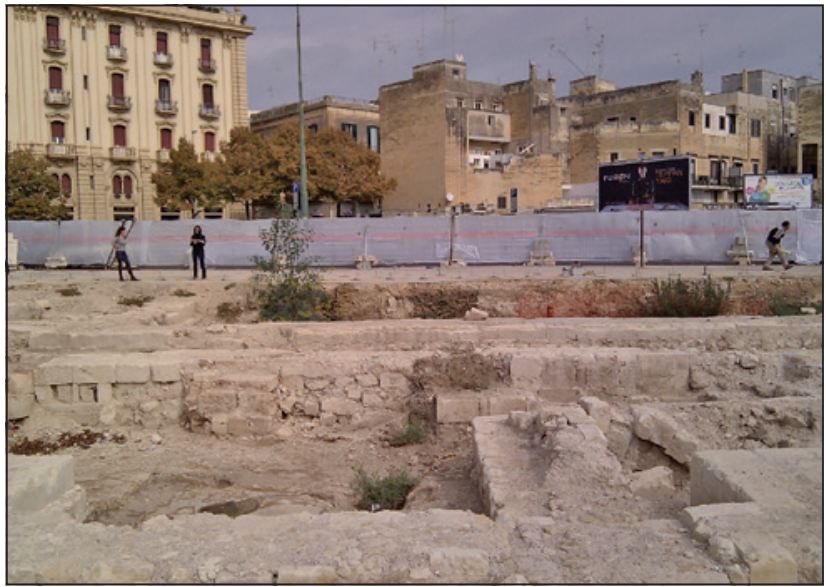

Figure 4 Photo showing the buried archaeological structures in an urban area, Lecce.

with the monastery plan view map but also other structures not reported in the map, hence a detailed GPR survey was required, in order to better detail the subsoil.

A GPR system GSSI SIR-3000 was used to investigate the area using a $400 \mathrm{MHz}$ antenna with Bridge Scan that has greatly facilitated the data acquisition. The trace length was $60 \mathrm{~ns}$ with 512 samples per trace and $0.0125 \mathrm{~m}$ trace increment. The survey area was divided into seven sub-areas surrounding the excavated area (Figure 5).

In each sub-area, the profiles are parallel and $1 \mathrm{~m}$ spaced. This area was already investigated by the same authors (Nuzzo et al., 2002) but the old GPR survey $(500 \mathrm{MHz}$ antenna) was made using a non-uniform spacing between the profiles (1-5) $\mathrm{m}$. The new survey has allowed a more detailed picture of the buried structures only in area A where the profile spacing was $1 \mathrm{~m}$.

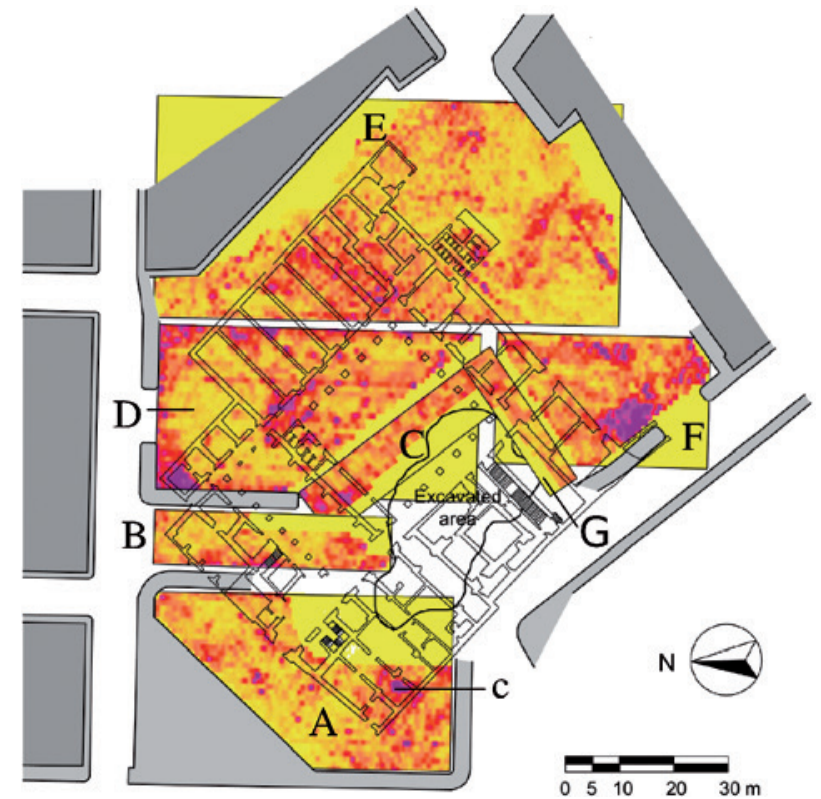

Figure 5 'Caserma Oronzo Massa'. Map of the ancient structures superimposed on the time slices (20-25) ns in each subarea $(A, B, C . . ., H)$.

Raw data was processed using Reflex v5.5 software. The main steps used in data processing were: time-zero correction, normalization, background removal, stack on 5 traces in order to obtain a trace spacing of about $6 \mathrm{~cm}$ and migration using an estimated mean velocity of $0.07 \mathrm{~m} / \mathrm{ns}$. Figure 6 shows the migrated radar section of a profile intersecting the cavity (c in Figure 5), brought to light by a later excavation. Visible anomalies are also visible at the ends of the large anomaly due to the cavity.

The time slices were computed (5 ns step), using the migrated sections. The most representative time slice, 


\section{Near Surface Geoscience}

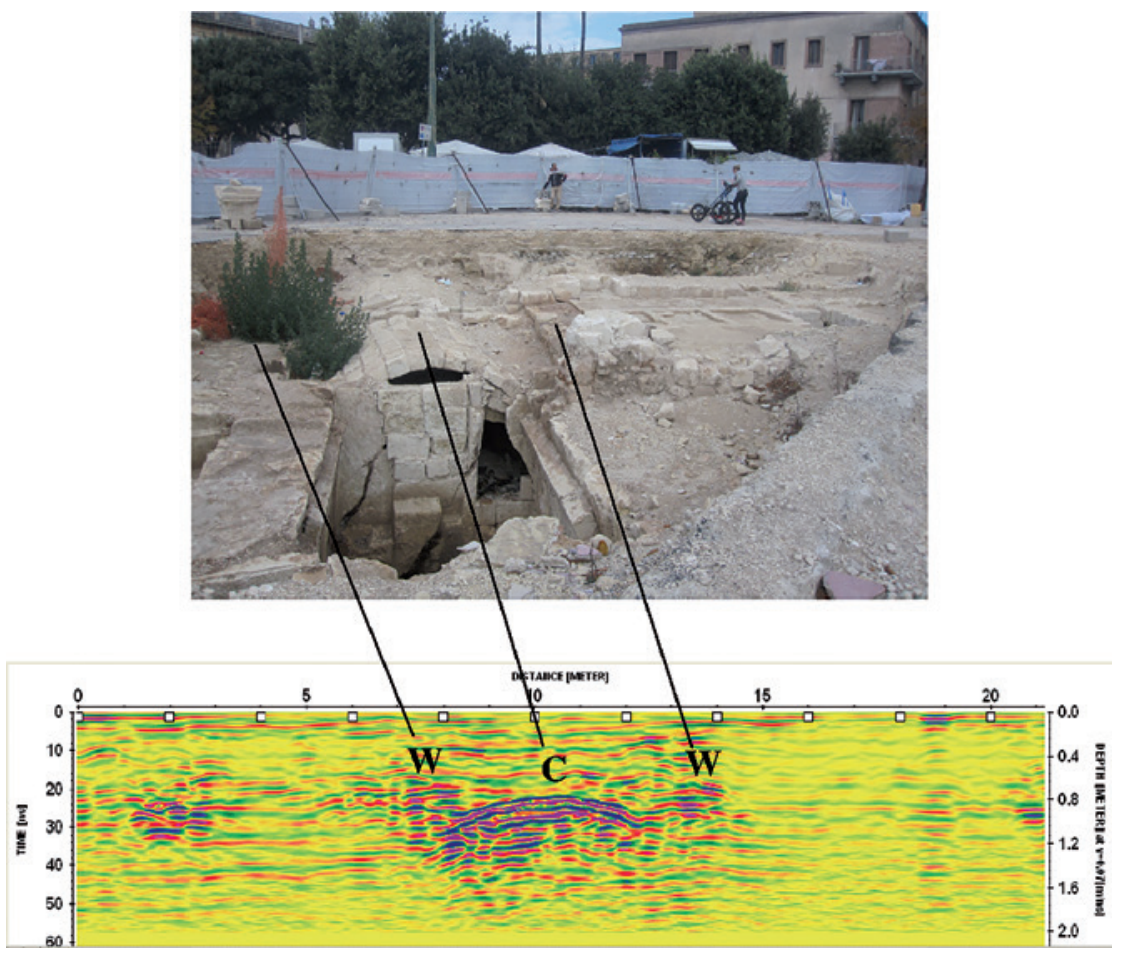

Figure 6 Migrated radar section of a profile intercepting the cavity $\mathrm{C}$ in the picture.
(20-25) ns, corresponding to an approximated depth range $(70.0-78.5) \mathrm{cm}$, superimposed on the old map of the 'Caserma Oronzo Massa' is shown in Figure 5 (Negri et al., 2014).

Many anomalies are present in this figure. Some of these, of great intensity, are located at the edges of the walls (W) of the old monastery. In the interior of the walls, the signal is very attenuated since the building material, a wet Miocenic calcarenite named 'Pietra Leccese', is characterized by a high value of electrical conductivity. Clutter noise due to the filling material, sometimes consisting of pieces of various sizes of the destroyed monastery, masked the anomalies due to walls making their identification more difficult. Numerous anomalies inside and outside the old map, due to subsequent changes in order to adapt the monastery to the new requirements of the barrack (walls, underground pipes), were brought to light by successive excavations.

Friuli-Venezia Giulia (NE-Italy) offers a large variety of funerary mounds that date back to the Bronze Age (Cassola and Corazza, 2002). Some of them are preserved and untouched by looters and human activities while others have been partly reshaped or completely destroyed.

The Barazzetto Tumulus (Coseano, Italy) is a possible remnant of a Bronze Age tumulus and an example of complicated conditions with the successive use of traces of previous cultural heritage. The tumulus has an irregular shape (Figure 7a), approximately $33 \mathrm{~m}$ in diameter and $1.8 \mathrm{~m}$ in height. A small church is on top of the mound and stonewalls border part of its southern and western flanks.
We used a combination of seismic transmission tomography and multi-offset reflection ground-penetrating radar (Forte and Pipan, 2008). We obtained 576 seismic records with 24 geophones at an approximate $15^{\circ}$ angular spacing, surrounding the mound at ground level, and 24 shot positions located midway between sensors (Figure 7b, Figure 8a). Lower velocity values (about $600 \mathrm{~m} / \mathrm{s}$ ) are observed in the outer part of the mound: a high velocity area oriented NE-SW is in the central part (velocities greater than $900 \mathrm{~m} / \mathrm{s}$, Figure $8 \mathrm{~b}$ ).

The continuous black line in Figure $8 \mathrm{~b}$ marks the border of the high velocity sector (average velocity greater than $900 \mathrm{~m} / \mathrm{s}$ ). The dotted black line is the likely margin of the ancient funerary mound while the external, low-velocity areas are the possible result of rehashes or enlargements of the original structure. High velocity zones inside the area marked by the dotted blue line correspond to the stonewalls along the flanks of the tumulus (Figure 7a).

The high velocity anomaly is due to layers of pebbles and cobbles that were used to shelter the funerary chamber. Final results of tomographic inversion show that the high-velocity zone extends beneath the church (Figure $8 \mathrm{~b}$ ).

A grid of 26 multi-offset $(60$ to $150 \mathrm{~cm}$ ) and multifrequency (300 and $500 \mathrm{MHz}$ ) GPR profiles integrates the seismic survey (Figure 7b). Velocities obtained from multioffset data indicate average values of around $13 \mathrm{~cm} / \mathrm{ns}$.

A strong reflector (in yellow, Figure 9a) at an average $180 \mathrm{~cm}$ depth shows location and extension corresponding to the seismic high-velocity zone. Labels D indicate targets with linear dimensions smaller than $1 \mathrm{~m}$. At the beginning 
of the profile discontinuous and dipping reflectors, likely to be due to lenses of sediments laid out during the construction, are also imaged. The pseudo 3D GPR data analysis (Figure 9b, Figure 9c) confirms the previous interpretation: the highly reflective area has in fact an almost perfect matching with the high seismic velocity zone (Figure $8 \mathrm{~b}$ ).

It is therefore possible to identify depth and location of the inner pebble/cobble layer sheltering the funerary chamber by means of two independent non-invasive techniques.

Historical and archaeological studies have shown the strategic importance that the region of Tavoliere (Apulia, Southern Italy) had in past centuries from the Neolithic to the Middle Ages.

With the aim of analysing the deep transformations that have taken place (development of rural and urban settlements, use of the landscape, etc.) in this very extended territory, a multi-year research programme, involving several competences in different areas (history, archaeology, economy, archaeometry and geophysics), is now in progress. The geophysical contribution to this multi-disciplinary research consists of a non-invasive investigation mainly combining remote sensing data and magnetic surveys in order to locate and identify buried archaeological features in different regions of this very large plain. The most recent study was carried out in 2014 and focused on the site of Corleto, an important medieval settlement which was continuously inhabited from the $10^{\text {th }}$ to the $14^{\text {th }}$ centuries. Satellite QuickBird images were used to obtain an up-to-date synoptic view of the study area; archaeological features extracted were then further investigated by a groundbased high-resolution magnetic survey.

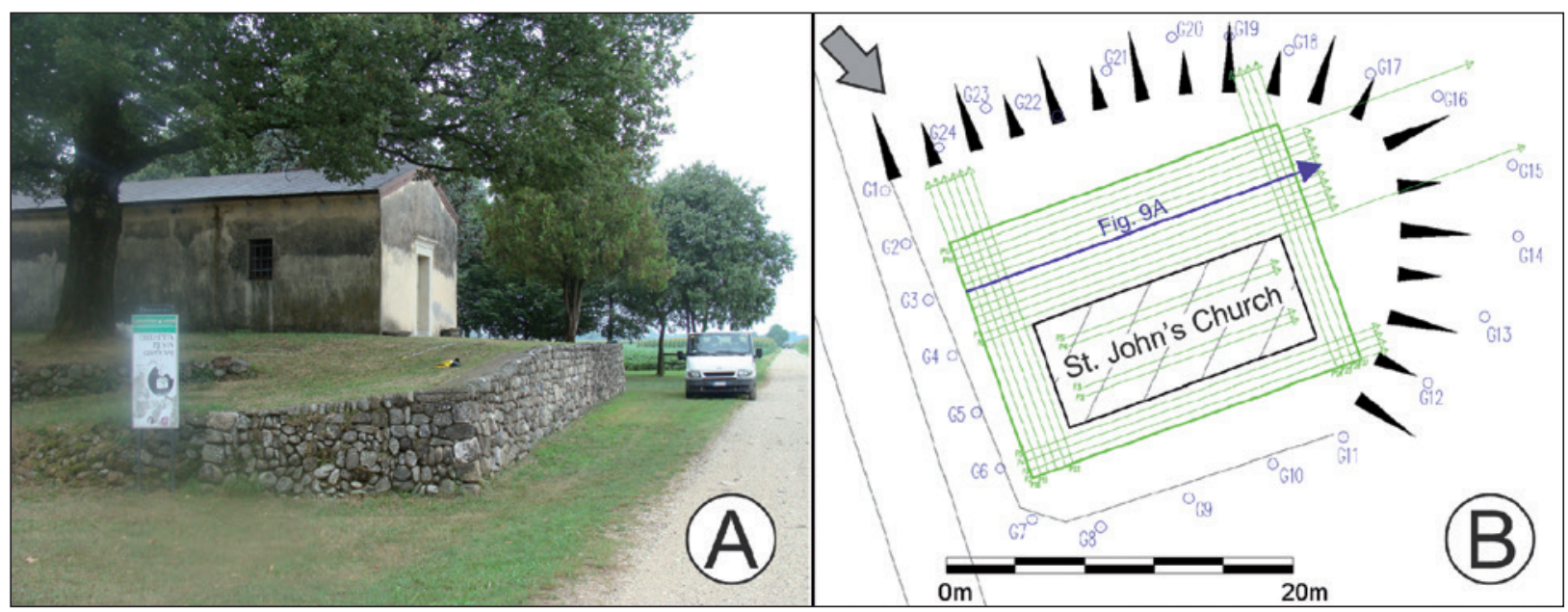

Figure 7 a) Photograph of the the surveyed tumulus of Barazzetto (Coseano, Italy) with St. John's church; b) Geophones and GPR survey locations. The grey arrow shows the point of view of the picture a), while the thick blue segment highlights the location of GPR profile shown in Figure 9a.
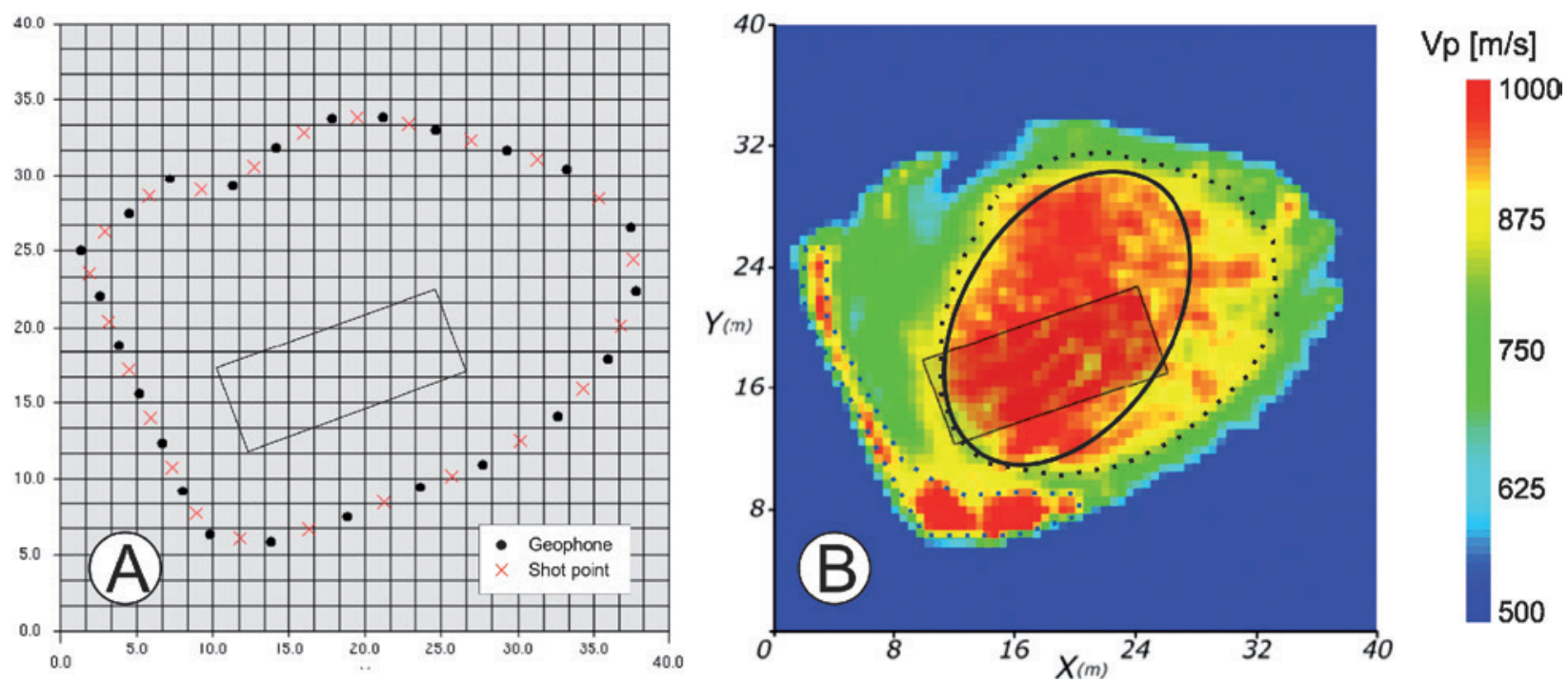

Figure 8 Results of seismic tomography. a) Location of receivers (circles) and sources (crosses); b) tomography traveltime inversion results. The ellipse marks the area with highest seismic velocities, the black dotted line shows the limit of the probable original structure, while the blue dotted line highlights the external stonewall, which is characterized by high velocity anomalies. The rectangle marks on both figures the limit of St John's church. 
Figure 9 Synthesis of GPR results. a) Example of processed and interpreted $300 \mathrm{MHz}$ profile: the yellow dotted line marks the top of a high reflective structure, while $D$ labels indicate diffraction hyperbolas related to small size objects. b) Survey map: the black dotted lines mark the limits of the high reflective zone, obtained by interpolating the blue circles; red circles are related to localized diffractions. c) Instantaneous amplitude map at a depth of 2.2 metres.
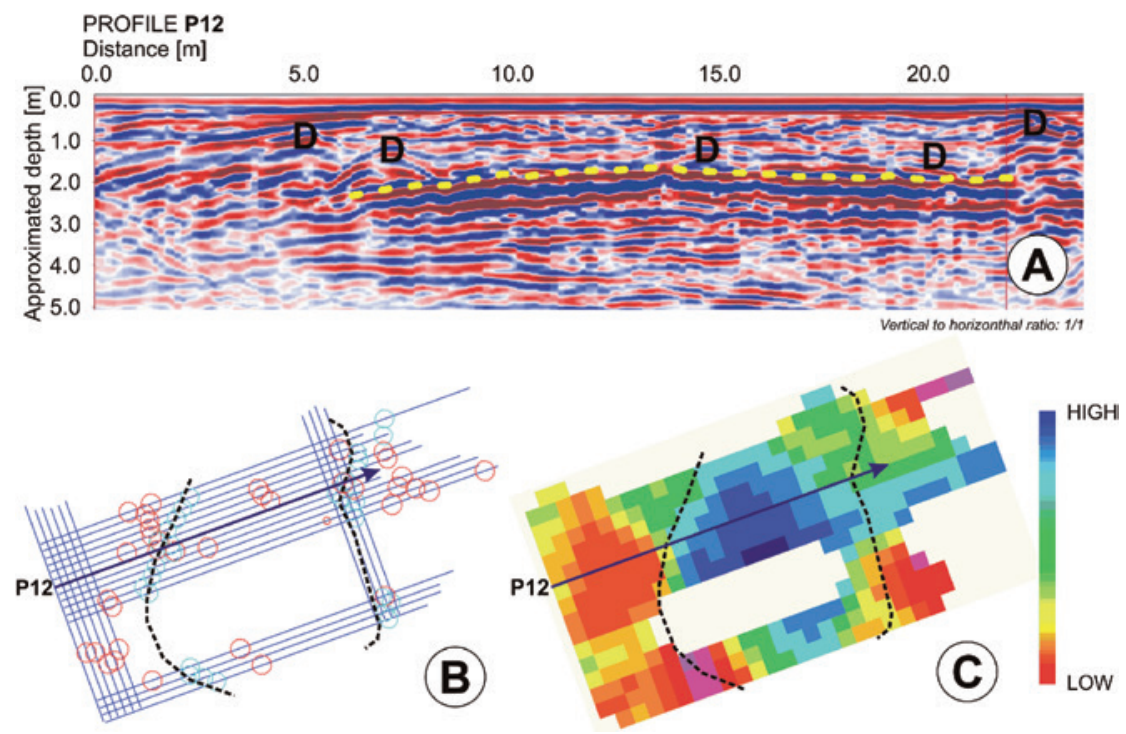

The selected QuickBird dataset was acquired on 27 May 2006 in a period of the year generally characterized by the best cropmark visibility and is composed of two types of images: a multi-spectral and a panchromatic one. The spatial resolution is $2.69 \mathrm{~m}$ and $0.67 \mathrm{~m}$ at nadir for MS and PAN respectively. In order to improve the visibility and recognition of cropmarks related to the buried structures the remote-sensed data were processed with different algorithms of panscharpening and with the application of spectral and spatial enhancement filters (Noviello et al., 2013). Figure 10 shows a result of this processing.

As regards the magnetic prospection, the surveyed area (approximately 120,000 $\mathrm{m}^{2}$ ) was firstly gridded in $40 \mathrm{~m} \mathrm{x}$ $40 \mathrm{~m}$ squares and then geocoded to the UTM co-ordinates system through high-accuracy DGPS measurements.

Magnetic data were acquired in bidirectional mode along parallel profiles $50 \mathrm{~cm}$ apart with a Geometrics G858 magnetometer (sampling rate $10 \mathrm{data} / \mathrm{sec}$, sensitivity 50 pT) arranged in duo sensor configuration (Ciminale et al., 2007). While executing the survey, a first data visualisation and their rough processing, directly insitu, contributed to a well plan. In total, more than 1,800,000 measurements were recorded with a mean spatial resolution of $0.5 \mathrm{mx}$ $0.125 \mathrm{~m}$.

All the dataset was processed applying routines specifically implemented and based on statistical criteria (Ciminale and Loddo, 2001) in order to minimize undesirable contributions (spikes, stripes and zigzag effects) which very often affect recorded data reducing, also strongly, the readability of archaeological signals. The subsequent application of DIP techniques enabled very high definition raster images. Figure 11 shows the final magnetic mosaic.

It is clear at first glance that all of the prospected area has anomalies of great archaeological significance.
The information resulting from magnetic data, in respect to the satellite imagery, allowed a more detailed and complete reconstruction of the medieval settlement. The magnetic anomalies appear sharper then the remote sensed signals, better outlining not only the general plan of the site but also very small features.

Either magnetic and satellite data were inserted into a GIS environment (Caggiani et al., 2012) where multi-sources of information could be effectively integrated for a very significant landscape archaeology reconstruction or the informative system can provide different details and types of information zooming from a wider territorial context to a very precise mapping of the buried structures.

The Roman Forum is one of the most famous and important archaeological places in the world. In the past the Italian Ministry of Cultural and Environmental Heritage investigated the columns of the Antonino and Faustina temple (141 AD) located in the Roman Forum (Figure 12) with the aim of restoring them.

With this aim, we performed a seismic investigation by seismic refraction and seismic transmission tomography. The columns of the Pronaos of the temple are $15 \mathrm{~m}$ long and have a diameter of about $1.5 \mathrm{~m}$. The columns formed of cipollino marble composed of mica and calcite beds, show clear characteristics of schistosity. The beds of mica and calcite extend up the full height of the columns. On the surface, the columns show a high degree of decay due both to their age (2000 years) and to air pollution during the last century. The mica is now superficially broken up and decayed, and the columns themselves show fractures and cracks.

We performed a seismic refraction along two lines for each column. These lines were located vertically, at diametrically opposite sides, in order to determine the P-wave velocity values that characterize the marble. In the seismic 


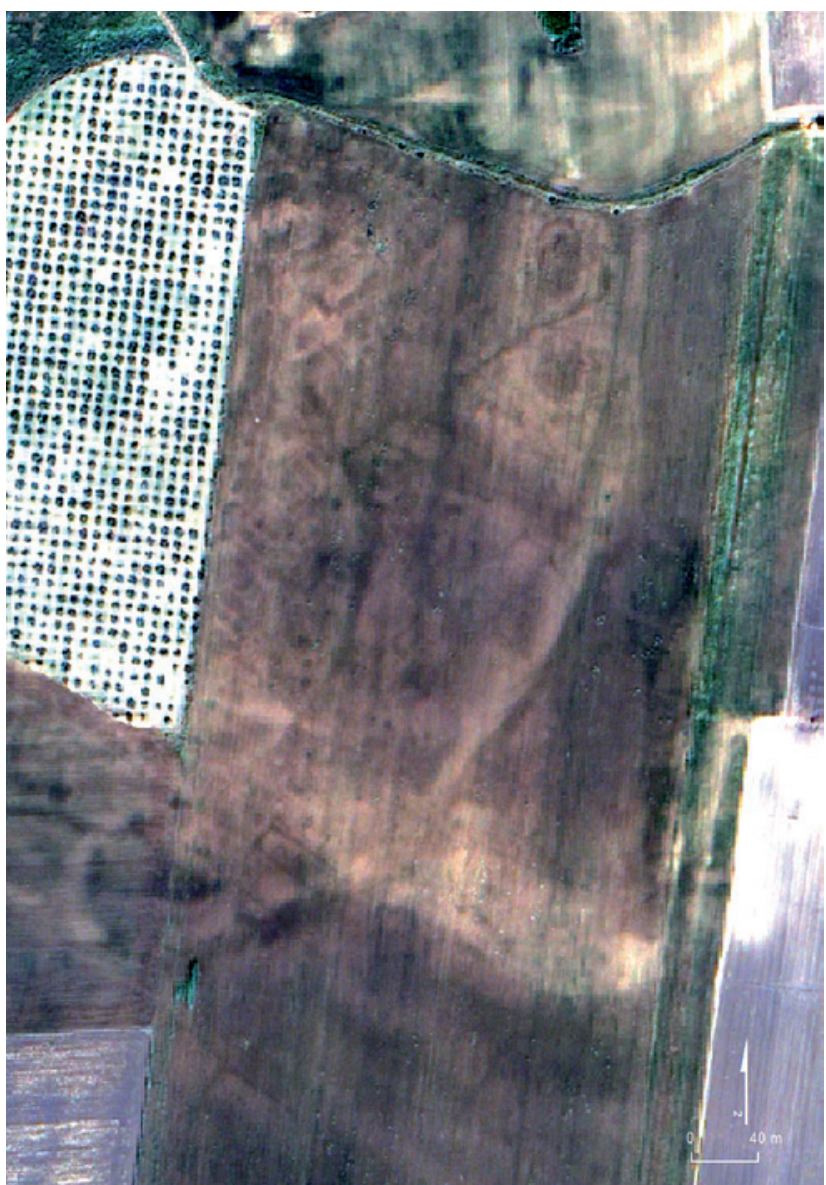

Figure 10 Processed satellite image. Data have been first pansharpened (Subtractive Resolution Merge algorithm) to increase the spatial resolution and then enhanced through the application of a spatial filter (Wallis Adaptive).

tomographic survey, we located 12 planes (circular sections), $1 \mathrm{~m}$ apart vertically. In each plane we placed six sensors and six shots around the column equally distributed (Figure 13).

For both techniques we used piezo-electric sensors with a cut-off frequency of $4 \mathrm{kHz}$ and a 24-channel digital recorder with a sample rate of $100 \mu \mathrm{s}$. A 2-kg hammer was the source.

By the comparison between the two seismic surveys, (refraction and tomography), we argued that the marble showed anisotropic characteristics. While in seismic refraction the inner zone velocity is $4.6-5.2 \mathrm{~km} / \mathrm{s}$, while in seismic tomography the inner zone is characterized by a velocity around $2.5 \mathrm{~km} / \mathrm{s}$.

For this reason, we repeated the tomography survey using the hypothesis of transversely isotropic material. We assumed that the main directions of the anisotropy were co-planar to it and positioned 13 sensors and 13 source points for a total of 169 ray-paths. We increased the number of paths both to improve the angular coverage and to compensate for the fact that we had to invert simultaneously the two slowness fields sx and sy that corresponded to the main directions of the anisotropy. We increased the number of

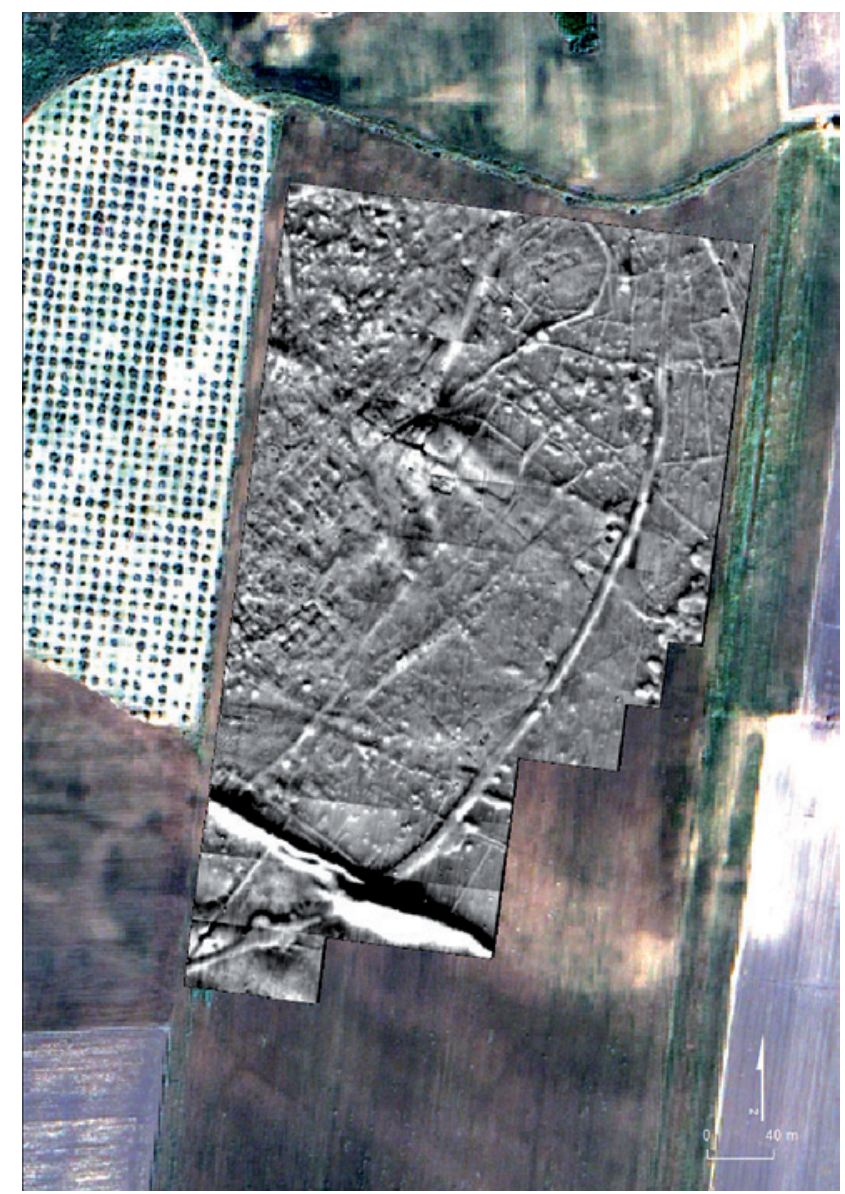

Figure 11 The anomalous magnetic field displayed in 256 grey tones in the interval [-13 nT black, $+12 n T$ white], while the original values were typically in the interval [-98 nT, $+60 n T]$.

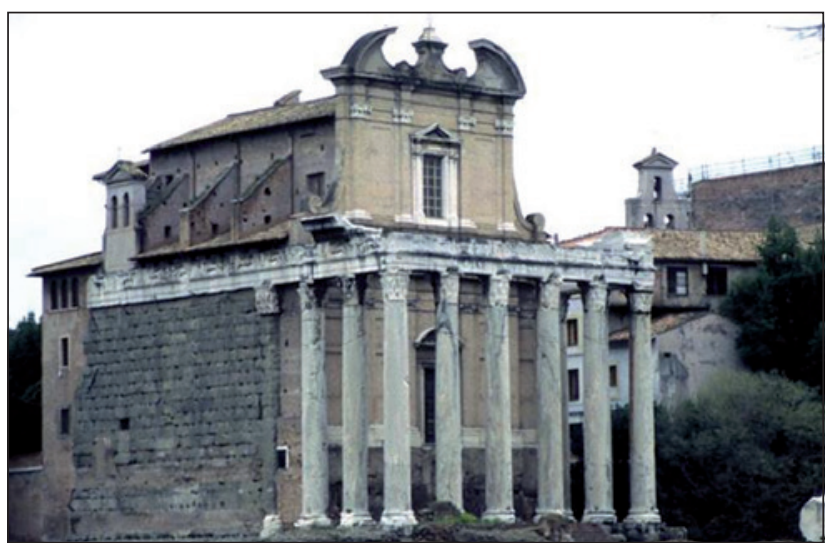

Figure 12 Antonino and Faustina temple (141 AD), Rome.

cells to 25 , with variable dimensions cells. The dimensions of the cells were a compromise between the Fresnel ray theory and the depths of the layers that seismic refraction detected.

The velocity fields of the main directions are shown in Figure 14. In Figure 14a, the high velocity field (vx) shows 
Figure 13 Comparison between tomography and refraction results.
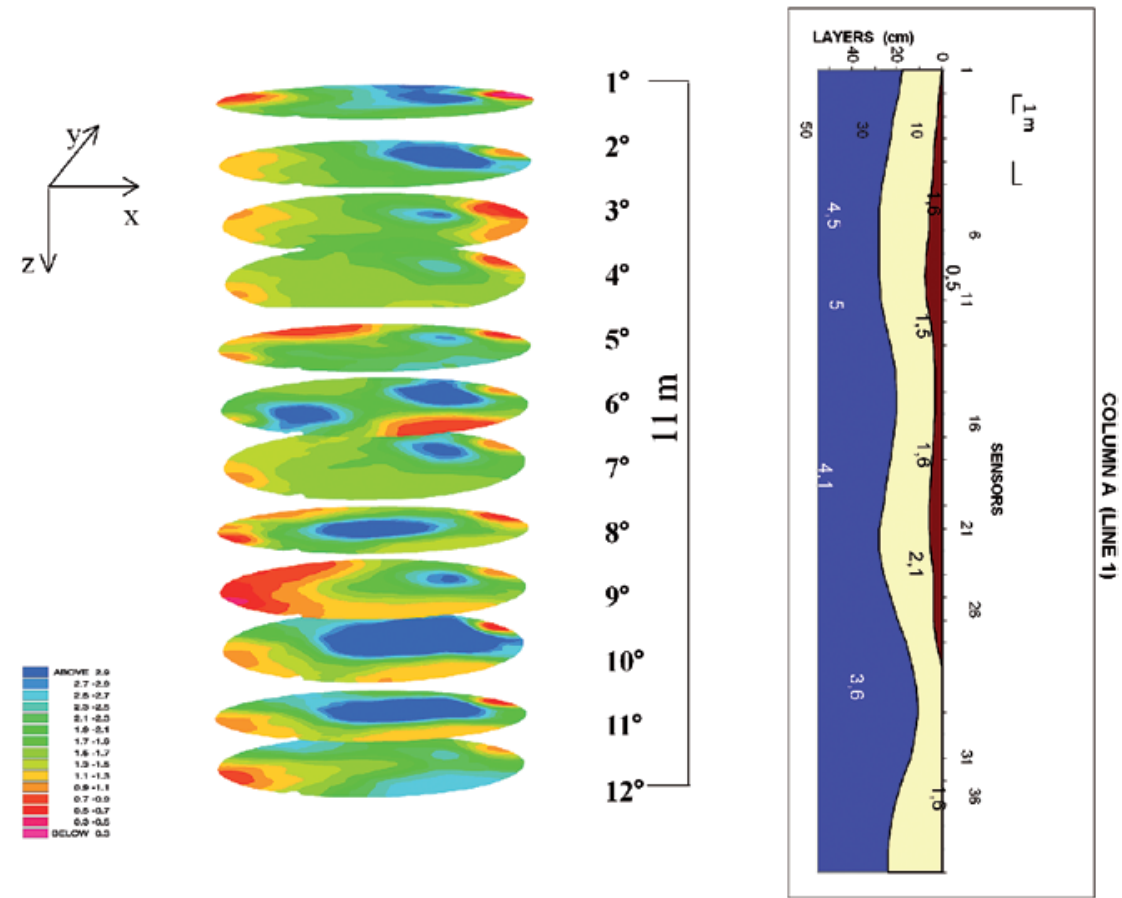

marked variation in the range $0.8-4.8 \mathrm{~km} / \mathrm{s}$ where in the inner zone the velocity reaches $4.8 \mathrm{~km} / \mathrm{s}$. The trend of the velocity field is parallel to the schistosity of the material. In this case, the highest velocity value that we obtained was the same as that obtained using the seismic refraction, confirming the hypothesis of anisotropic behaviour of this marble. Figure 14b) shows the low velocity field (vy) to be fairly uniform, with values ranging from $0.8-2.0 \mathrm{~km} / \mathrm{s}$.

To compare the two results we considered data-misfit for both the isotropic and anisotropic tomographic inversion (Figure 15). For the isotropic model (Figure 15a), the data-misfit shows a trend that depends on the direction in which the ray travelled (i.e. in some cases we underestimated the velocity and in others we overestimated the velocity). It explains the trend of the curve that interpolates the differences between the model and the field data. In the case of the anisotropic model, there is no dependence on the direction of the ray-paths (Figure 15b), therefore a better approximation is obtained.

The archaeological Museum of Rome (Museo delle Terme di Diocleziano) called for an investigation of a marble slab (II-III century AD) (Figure 16). GPR and Ultrasonic tomographies were used to investigate the slab and in particular the fractures due to a fall down during a transportation for an exhibition (Capizzi and Cosentino, 2011; Cosentino et al., 2011).

The ultrasonic measurements were carried out with the TDAS 16 instrument produced by the Italian Boviar srl and receiver and transmitter probes with a central frequency of $55 \mathrm{kHz}$. The survey was performed throughout the whole

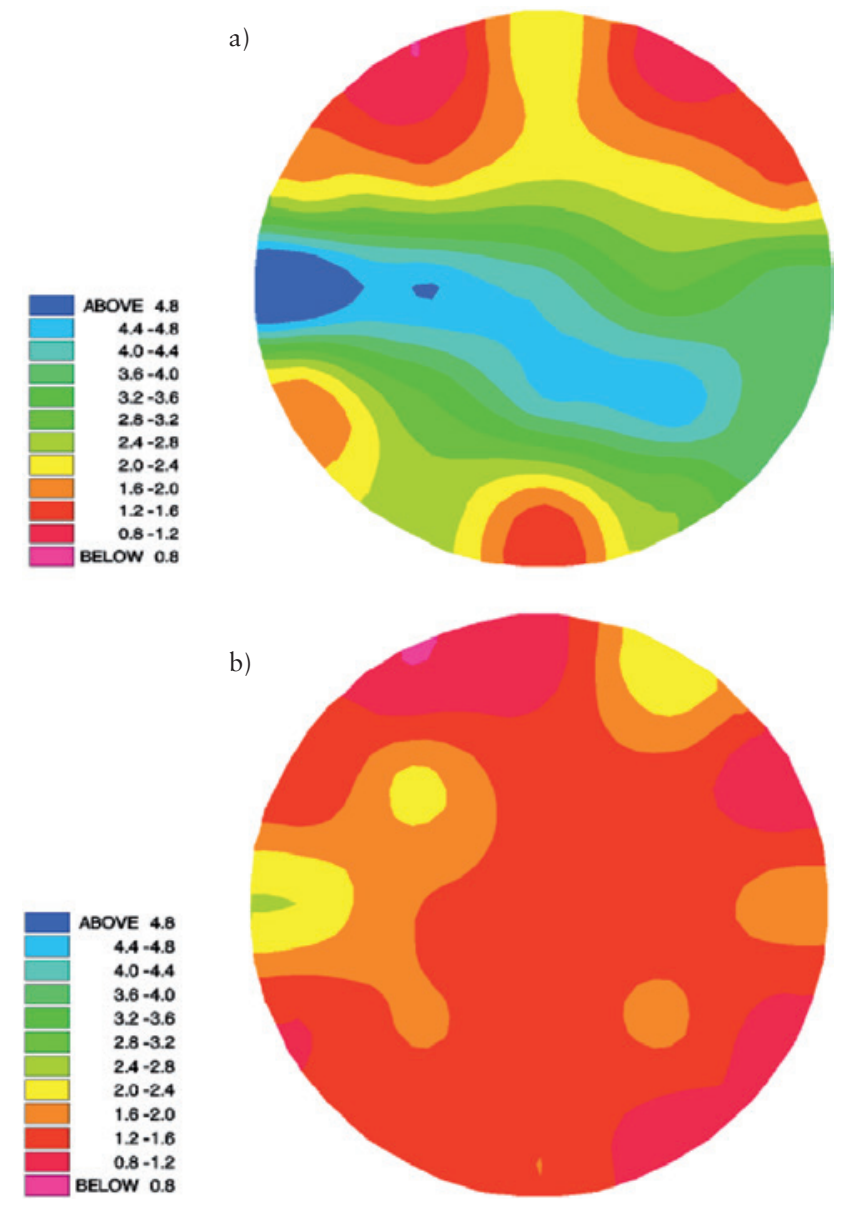

Figure 14 Field velocities. Higher a), lower b). 
volume of the slab. Plasticine was used to minimize the surface roughness between the probe and the surface of the slab.

The acquisition was realized using 65 measurement points, 40 distributed on the thickness of the slab side and 25 on the relief. The distance between two consecutive probe positions was set to $100 \mathrm{~mm}$. A total of 961 signals were acquired and processed.

A manual picking procedure was assumed to extract traveltimes of elastic waves. Before processing, tomographic data were filtered by removing the velocity values lower than $2000 \mathrm{~m} / \mathrm{s}$ and higher than $6000 \mathrm{~m} / \mathrm{s}$.

A tomographic model was calculated using elementary cells of size $5 \times 5 \times 4.5 \mathrm{~cm}^{3}$.

The tomographic model (Figure 17) shows non-homogeneous velocity values inside the volume of the marble slab, with a minimum velocity value of about $1000 \mathrm{~m} / \mathrm{s}$ and a maximum of about $5000 \mathrm{~m} / \mathrm{s}$. The low values of velocity indicate the decay of the marble, especially in correspondence of fractures.

GPR surveys were carried out with the IDS K2 control unit and an IDS Aladdin Full Polar $(2000 \mathrm{MHz})$ antenna. The trace length was set to $5 \mathrm{~ns}$, of which only 2.5 ns was
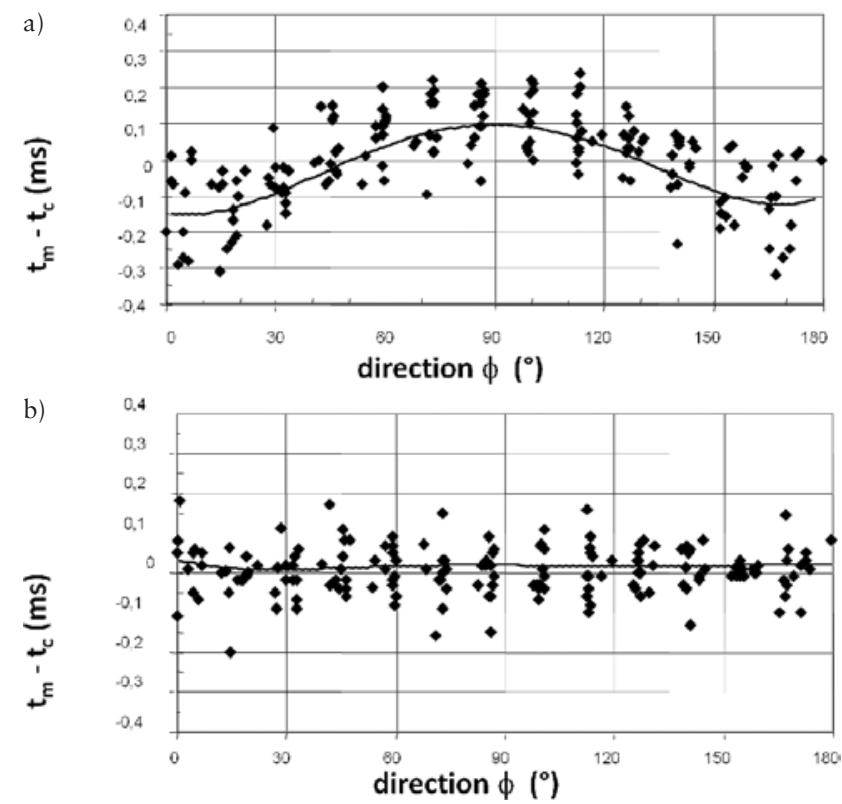

Figure 15 Diagrams of the difference between the calculated data set tm and the field data set tc in the cases of (a) isotropic tomography and (b) anisotropic tomography.
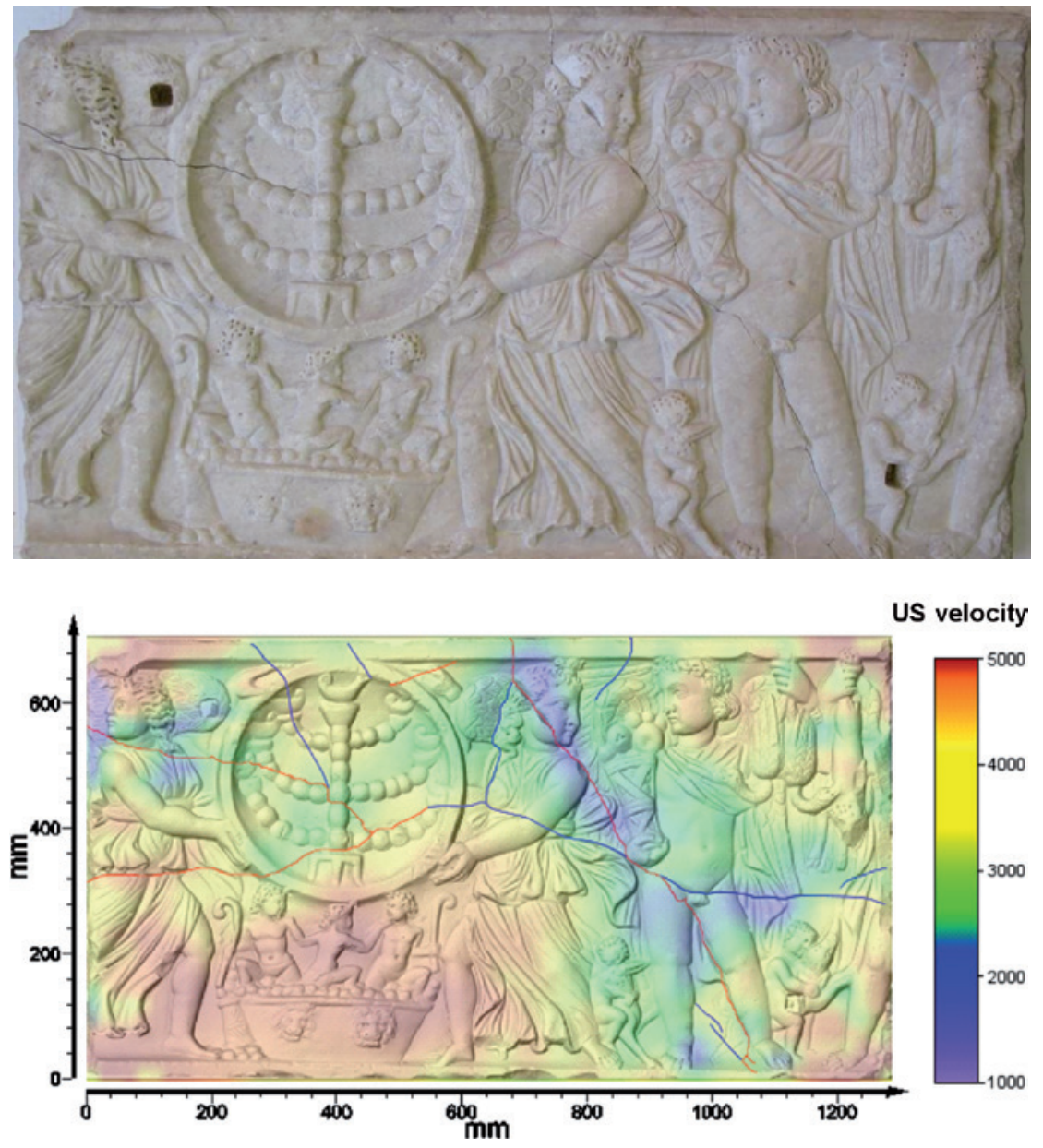

Figure 16 The marble slab (II-III century $A D$ ), Museo delle Terme di Diocleziano, Rome. 


\section{Near Surface Geoscience}

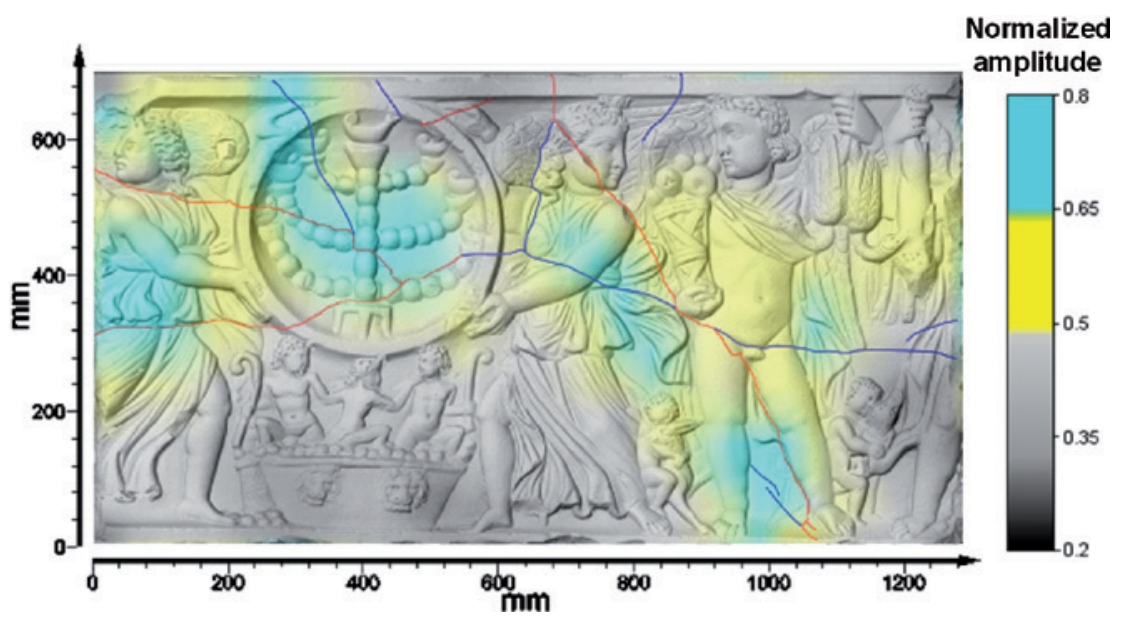

Figure $182 D$ GPR tomography superimposed to the slab image.

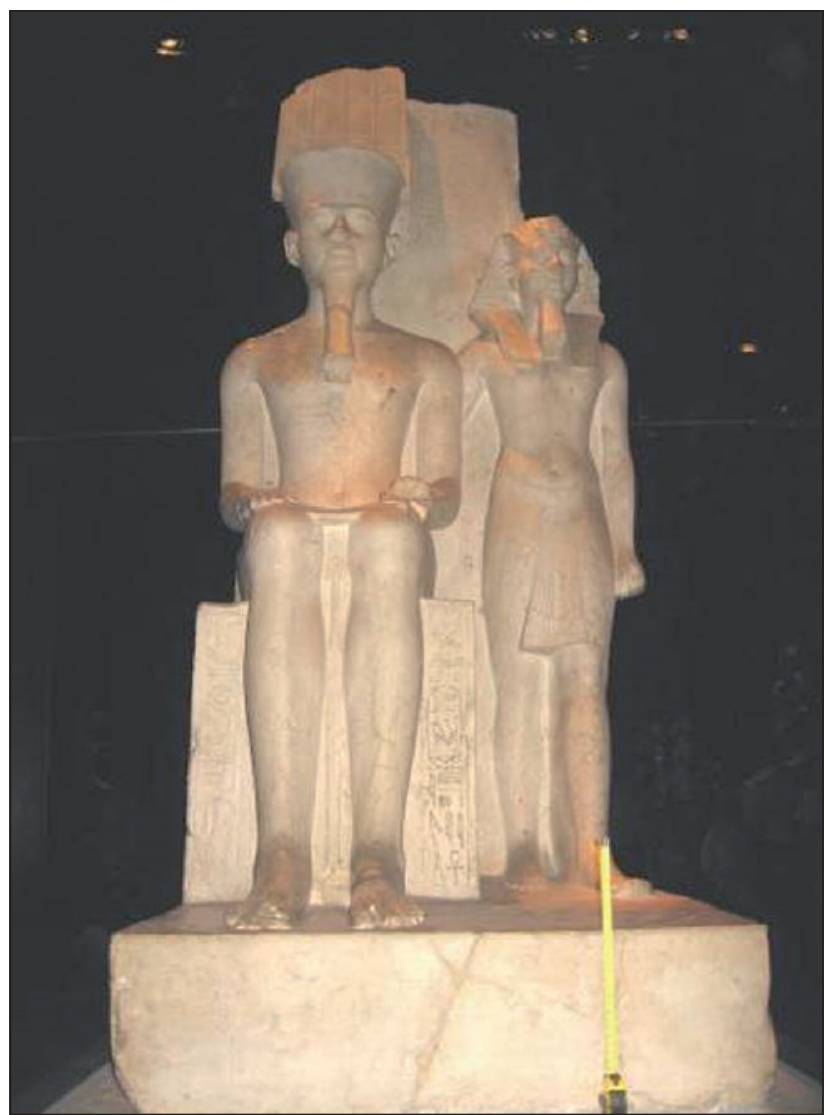

Figure 19 The statue of Pharaoh with god Amun, Museo delle Antichità Egizie, Turin.

considered, which allowed us to investigate the whole thickness (about $5 \mathrm{~cm}$ ) of the marble slab.

Considering the direction of maximum elongation of the slab, 12 longitudinal and 7 transverse profiles were acquired. The electromagnetic wave velocity in the marble was estimated to transform the traveltimes of reflected waves in the depth of the reflectors. The resulting velocity value was $0.06 \pm$ $0.005 \mathrm{~m} / \mathrm{ns}$ corresponding to a dielectric constant of 25 .

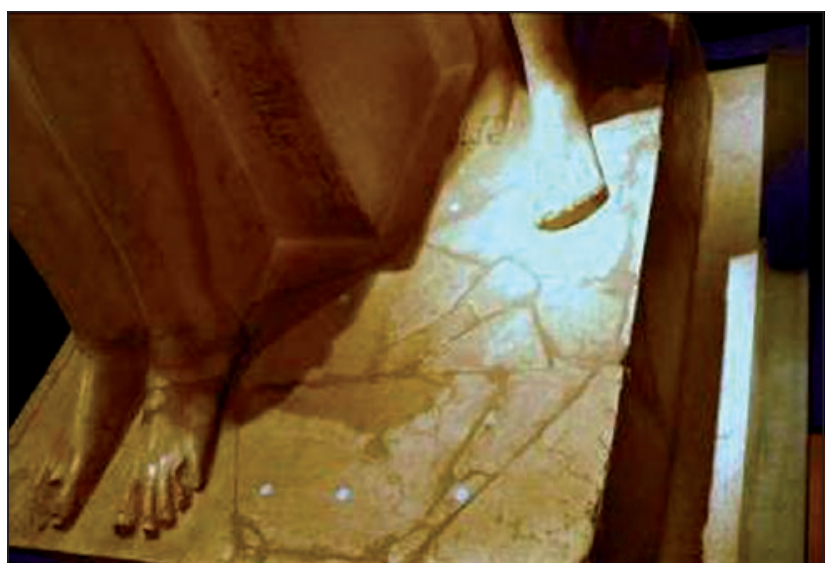

Figure 20 The basement of the statue of Pharaoh with god Amun.

GPR profiles were processed with Reflex software, using a standard sequence: background removal, frequency filter, running average and envelope. Finally, GPR data were used to obtain some detailed tomographic images (depthslices) calculated with a procedure implemented in Matlab, choosing an analysis window of $0.25 \mathrm{~ns}$ along the time axis and $0.05 \mathrm{~m}$ along the distance axis. The depthslice presented in Figure 18 corresponds to the central depth of the slab. The scale of the amplitudes of the map presented was normalized to the maximum value recorded.

GPR tomography shows a strong correlation with observable fractures in the slab, and therefore also with ultrasonic tomography. The detected anomalies correspond to changes in electromagnetic properties probably due to metallic elements of reinforcement.

Unfortunately, it was not possible to examine the back of the slab, to verify if the detected anomalies were due to the presence of metallic elements in the support.

In the Museo delle Antichità Egizie of Turin there is one of the largest collections of Egyptian antiquities in the world. The Fondazione Museo delle Antichità Egizie di Torino, who manages the museum, follows the policy of lending some 
particular pieces for temporary exhibitions abroad. This activity, however, involves the moving of very precious and fragile objects, which often underwent restoration works in the past. Unfortunately, often there are not any detailed or scientific reports about these restoration works. At the end of 2008 one of the masterpieces of sculpture of the museum, the Pharaoh with god Amun (Figure 19), was required for the temporary exhibition Ancient Egypt in Torino in Japan.

The Fondazione asked us to estimate how pervasive were the fractures in the basement (Figure 20) and to evaluate if the bodies and the throne were really intact. To answer these questions, GPR profiles on the back of the statue and on the basement were carried out along with two parallel ultrasonic tomographies (Sambuelli et al., 2011).

The GPR measurements were made with an IDS K2 control unit. An IDS Aladdin Full Polar $(2000 \mathrm{MHz})$, a GSSI mod $5100(1500 \mathrm{MHz})$ and a GSSI $3100(1000 \mathrm{MHz})$ antennas were utilized. For each basement side, with the exception of the back side, three parallel profiles, $6 \mathrm{~cm}$ spaced with the GSSI5100 , were acquired. The sampling frequency was $64 \mathrm{GHz}$, the trace length was $32 \mathrm{~ns}$ and we acquired, on average, 625 traces $\mathrm{m}^{-1}$. The upper part of the sculpture, of the figure of Amun and the Pharaoh, was investigated in reflection mode with the $2000 \mathrm{MHz}$ antenna. From the back of the sculpture, a mesh of

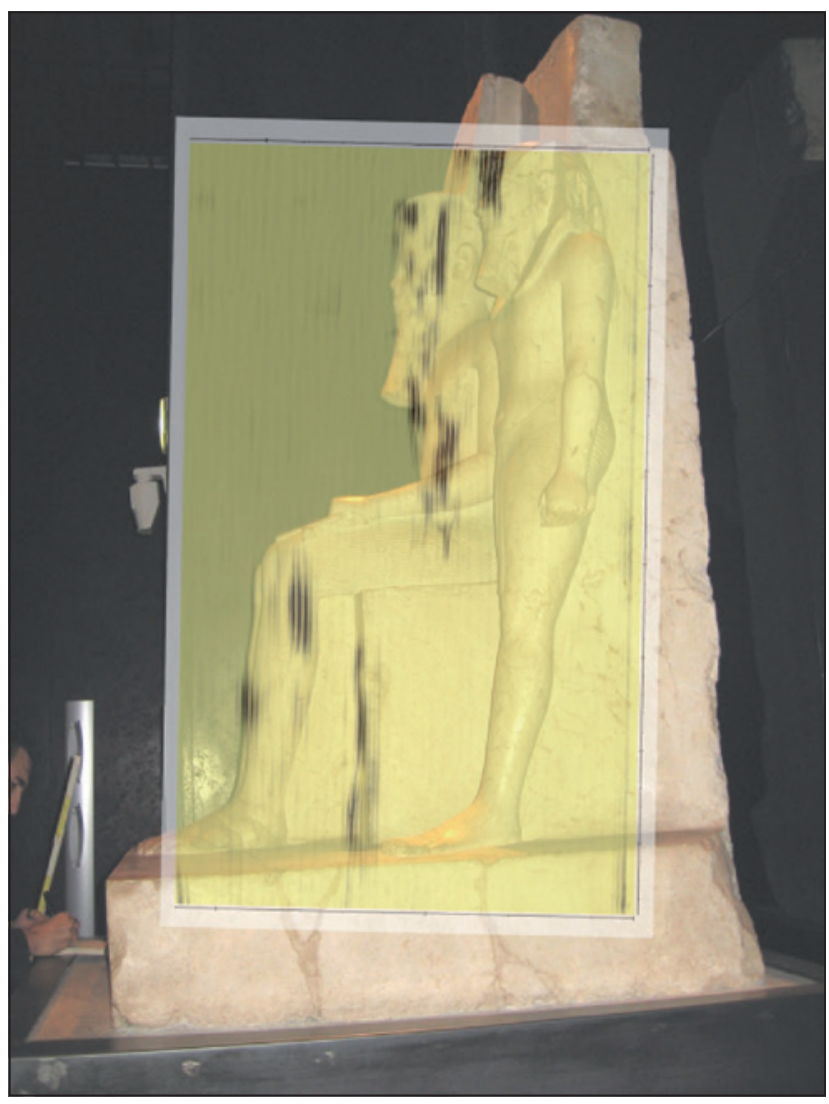

Figure 21 Radargram obtained from a vertical profile behind the body of Amun sitting on the throne. roughly 20x20 cm consisting of 15 horizontal profiles and four vertical profiles was acquired. With some tests in transparency mode with the $1500 \mathrm{MHz}$ and $1000 \mathrm{MHz}$ antenna on the opposite sides of the basements and of Amun's throne the electromagnetic wave velocity $(\mathrm{v}=0.109 \pm 0.005 \mathrm{~m} / \mathrm{ns})$ was estimated. Raw data were processed according to the following steps: trace editing, zero time correction, dewow, time

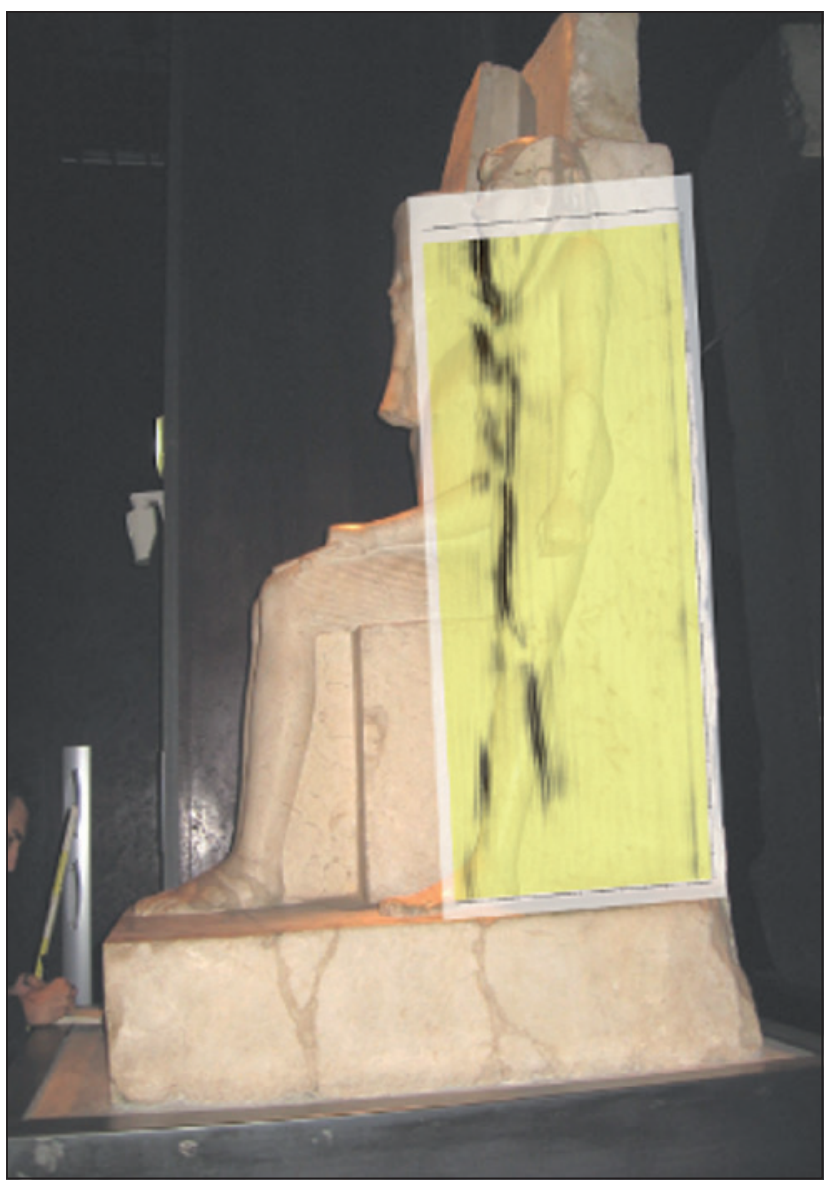

Figure 22 Radargram obtained from a vertical profile behind the body of Pharaoh standing alongside of Amun.

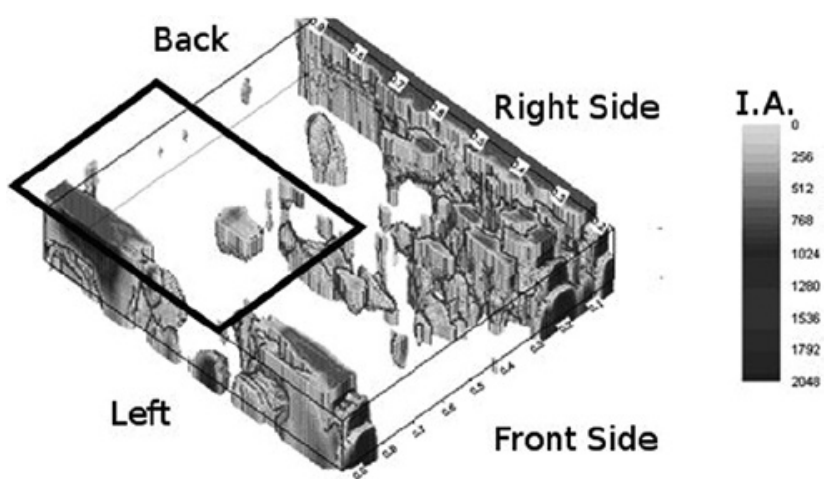

Figure $233 D$ rendering of the instantaneous amplitude obtained on the basement of the statue of Pharaoh with god Amun. The rectangle shows the position of the throne. 
compression by down sampling at $16 \mathrm{GHz}$, time cut, diffraction stack, spectral whitening and instantaneous amplitude.

The upper part of the statue was found to be intact: the only significant reflections in the radargrams were the ones pertaining to the surface of the sculpture opposite to the one where the antenna slid (Figure 21 and Figure 22).

A quite different imaging resulted from the $3 \mathrm{D}$ rendering of GPR processed profiles in the basement (Figure 23) where the reflections suggested that the basement was an assembly of marble pieces cemented with a mortar.

\section{Conclusions}

In this paper we present a partial, although significant, report of the activities of some Italian geophysicists involved in cultural heritage studies. The variety of the problems to be solved needs different geophysical and microgeophysical methodologies for exploring, analysing and monitoring archaeological sites, artworks and historical monuments.

The broad range of the sizes of objects to be investigated required and requires a continuous improvement both of the instruments and of the interpretation tools.

Marcello Ciminale passed away, suddenly, on 4 July. This paper is dedicated to his memory. Luigi, Michele, Sergio, Tatiana, Ettore, Salvatore, Emanuele, Patrizia.

\section{References}

Caggiani, M.C., Ciminale, M., Gallo, D., Noviello, M. and Salvemini, F. [2012] Online Non Destructive Archaeology; The Archaeological Park of Egnazia (Southern Italy) study case. Journal of Archaeological Science, 39, 67-75.

Capizzi, P. and Cosentino, P. [2011] Electromagnetic and ultrasonic investigations on a roman marble slab. Journal of Geophysics and Engineering, 8, S117-S125, doi:10.1088/1742-2132/8/3/S11.

Cardarelli, E. and de Nardis, R. [2001] Seismic refraction, isotropic anisotropic seismic tomography on an ancient monument (Antonino and Faustina temple ad 141). Geophysical Prospecting, 49, 228-240.

Cassola Guida, P. and Corazza, G. [2002] Udine, S. Osvaldo tumulo protostorico. Scavi 2002. Aquileia Nostra, 73, 754-57.

Ciminale, M. and Loddo, M. [2001] Aspects of Magnetic Data Processing. Archaeological Prospection, 8, 239-246.

Ciminale, M., Becker, H. and Gallo, D. [2007] Integrated Technologies for Archaeological Investigation; the Celone Valley Project. Archaeological Prospection, 14, 167-181.

Cosentino, P.L., Capizzi, P., Martorana, R., Messina, P. and Schiavone, S. [2011] From Geophysics to Microgeophysics for Engineering and Cultural Heritage. International Journal of Geophysics, 1-8, doi:10.1155/2011/428412.

Forte, E. and Pipan, M. [2008] Integrated Seismic Tomography and Ground-Penetrating Radar (GPR) for the High-Resolution Study of Burial Mounds (tumuli). Journal of Archaeological Science, 35, 2614-2623, doi:10.1016/j.jas.2008.04.024.
Goodman, D. and Piro, S. [2013] GPR Remote sensing in Archaeology. Geotechnologies and the Environment, 9, doi: 10.1007/978-3-64231857-3.

Negri, S. and Quarta, T. [2014] GPR survey for search archaeological structures in an urban area (Lecce, Italy). Proceedings GNGTS $-33^{\circ}$ Convegno Nazionale, Bologna, 25-27 November.

Noviello, M., Ciminale, M. and De Pasquale, V. [2013] Combined application of pansharpening and enhancement methods to improve archaeological cropmark visibility and identification in QuickBird imagery. Two case studies from Apulia, Southern Italy. Journal of Archaeological Science, 40, 3604-3613.

Nuzzo, L., Leucci, G., Negri, S., Carrozzo, M.T. and Quarta, T. [2002] Application of $3 \mathrm{D}$ visualization techniques in the analysis of GPR data for archaeology. Annals of Geophysics, 45, 321-337.

Piro, S., Goodman, D. and Nishimura, Y. [2003] The study and characterisation of Emperor Traiano's Villa (Altopiani di Arcinazzo - Roma) using high-resolution integrated geophysical surveys. Archaeological Prospection, 10, 1-25.

Sambuelli, L., Bohm, G., Capizzi, P., Cardarelli, E. and Cosentino, P. [2011] Comparison between GPR measurements and ultrasonic tomography with different algorithms: an application to the base of an ancient Egyptian sculpture. Journal of Geophysics and Engineering, 8, S106-S116, doi:10.1088/1742-2132/8/3/S10.

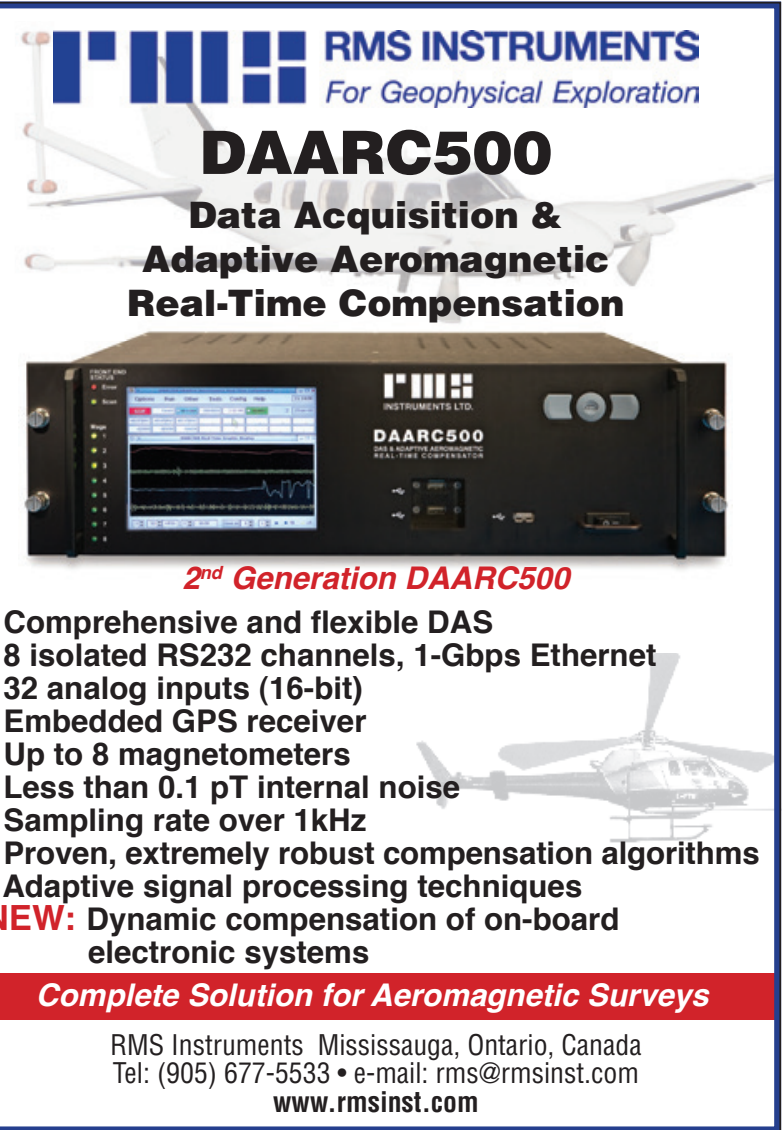

